\title{
Intermediality and Translation: Pedagogical Possibilities
}

TUTUN MUKHERJEE

\begin{abstract}
Translation is an important part of the learning process that facilitates inter-language exchange. When pedagogical processes have benefitted from integrated use of technology, it is desirable that translation should also call upon technology to make the translation exercise more vast, various and interesting for teachers, learners and translators. The paper explores the way media and technology can enhance understanding of life and literature. The aspects addressed are new demands on pedagogy and language use in contemporary times and the exploration of novel communication modes. The paper argues that inter-modal translations extend horizons of both appreciation and reception of literature.
\end{abstract}

Keywords: Translation, Intermediality, Inter-Modal Expression, Hermeneutics.

\section{Introduction}

The basic thrust of this paper is to explore the way media and technology can be integrated into teaching practice to enhance understanding and enjoyment of literature. The aspects addressed are new demands on pedagogy; the use of intermodal practices to make teaching and learning more interactive and engaging for the teacher and the learner; and sociology of literature in contemporary times. It also proposes intermediality as a useful method to make translation an explorative and shared endeavor for both the translator and the reader. The paper argues that inter-modal translations extend horizons of appreciation and reception. 
The fact cannot be over-emphasized that we live in a 'mediatized' or a 'media-saturated' world with the awareness that all our activities are permeated by media systems. All domains of lexicography, macro/inter/ intra-textualities, sociocultural and ideological interaction have absorbed the mediagenerated impact and have, as a result, undergone and consequently manifested radical changes in their use and expressivity. All modes of expression, especially the literary, are undergoing what Roger Fidler calls "mediamorphosis." Media has saturated our lives to such an extent that there is hardly a domain or a practice that remains unaffected. Media developments and co-relations between media have created new forms of representation which enable, as Chiel Kattenbelt explains, "new ways of positioning bodies in time and space; of creating time-space relationships; of developing new modes of perception; and generating new cultural, social and psychological meanings" (2). Hence, technologies shape our modes of thought and world-view. For us who are engaged in the process of knowledge acquisition and dissemination, the technological and digital interventions offer the opportunity to maximize the promise and the potential of the various medial forms towards devising literacies to not only gain new knowledge but also shape new ways of accessing and receiving/perceiving/storing knowledge. Increasing use of technology to mediate and represent 'realities' has opened up new avenues of research on the potential of human interaction through different streams of aural, acoustic, optic, typographic technologies which in combination can and has radically changed our perceptive, memorial and imaginative habits and in turn has changed the sociology of language use. From the first ever intervention of technology of the Gutenbergian kind, we have seen increasing dependency of knowledge circulation on technology until the tremendous paradigm shift that computerization, digitization and media saturation have 
brought. These times are no longer of mono-media use but of combination of media which when deployed enrich the teaching-learning process. Literature and language teaching and learning are innately accommodative of more than one media to aid understanding, have in fact affinity with other media. For example, language is taught with the help of roleplaying; drama is taught with the help performances; poems can be taught with the help of painting and music. These modes have been tried from earliest times. In contemporary times, class-room teaching can make use of computerized information to enhance understanding and appreciation. Towards this end intermediality shows immense pedagogical promise.

\section{Understanding Intermediality}

'Intermedia' as usage and idea was suggested by Fluxus avantgarde artist Dick Higgins in 1968 to refer to the fusion or blending of artistic media or mixed media. In the words of Werner Wolf who has written clearly and comprehensively on "(Inter)mediality and the Study of Literature," explains intermediality to simply mean the participation of more than one medium within an artifact (2). He adds that in a broad sense intermediality would mean "transgressing of boundaries between conventionally distinct media" (3). Generally, teachers and students have competence in one medium, that is, one is generally mono-disciplinary or mono-medial. Intermediality would require knowledge if not adequate proficiency in more than one medium - for example, learners must acquire some competence beyond literature as for example in theatre, film, music, visual arts. Literature as a subject of study has always been very accommodative of plurimedial approaches for appreciation and understanding. The relevance of an artifact is definitely enhanced when it is perceived from a comparative media point of view. According 
to Jens Schröter, intermedia project a place of 'hybridity' where works in different media can be affiliated/fused at the conceptual level, thus enabling "a field of interpretative possibilities, a configuration of substantially indeterminate stimuli which the recipient employs for his "readings'." However, Schröter stresses that the differentiation between "intermedia" and "mixed media" is important to understand. Schröter cites Higgins' suggestion that in "mixed media" the mediated forms meeting can at any time be regarded by the viewer as separate while in "intermedia" or in "intermedial forms" a "conceptual" fusion occurs making it impossible to view only one of its origins and suggests an assembly of different forms, such as "graphic poetry," appears as an indivisibly "fusioned intermedium" (4).

I contend that the idea of intermedia can be traced back in history like 'inter-textuality'. It is my belief that the 'prototype' of inter- or even multi-modality, that means the use of different forms of expression to project and augment an idea has been explored by earlier creative minds also much before the intensive media infiltration into our knowledge systems. The most obvious instances are the association of the typographical with the optic, which is, combining and/or juxtaposing poems and paintings. Let me explain with examples from the literary and art scene in India in $19^{\text {th }}$ century Bengal which was in the throes of reviewing and reflecting upon new expressivities with the advent of print media and the encounter with knowledge systems of the Western world. It is interesting that from $19^{\text {th }}$ century, writers in Bengali aimed at the convergence of the arts. Transgressing the singularity of an expressive mode, these writers allowed their styles to suggest sedimentation of modes of expressivity and the possibilities of 'embedding' texts within texts. An obvious arena at that time was of 'humour' represented as farce and satirical writing of different kinds, published very 
often through private and small publishers referred to as 'bottala' books (literally, 'under the banyan tree'). One of the best minds of late $19^{\text {th }}$ century Bengal, Kaliprasanna Singha's brilliant satirical writings in Bengali as Hutom Pyanchar Noksha (1862) or 'Sketches of the Observant Owl' not only encouraged a 'noksha' genre (ethnographical sketch or map recalling the Persian naqsha which also suggests embroidery or tracery). Singha's Sketches inspired its translators to augment it with various kinds of musical parodies and artistic sketches and/or 'pata chitra' (scroll paintings) (see Maity). Singha focused on the socio-political aspects of the emergent 'new middle class' in the $19^{\text {th }}$ century under the colonial influence and was contemptuous of the changing culture of the city Calcutta, commenting on the vulgarity of the dissolute 'babu' who was deferential to the colonial masters but was patriarchally autocratic at home; his concubines; the nautch girls; charlatan priests; impudent servants, labourers and peddlers and so on; the many rituals and festivals of the people which exhibit elements of the Bakhtinian carnivalesque. The irreverence of tone and the racy and amusing commentary of the writer on the diminishing moral and ethical standards were praised by Bankim Chandra Chatterjee, an eminent writer of the time, who drew comparison with Charles Dickens' Sketches by Boz. Other than satirical songs, the 'sketch' style found reflection in yet another mode as follows:
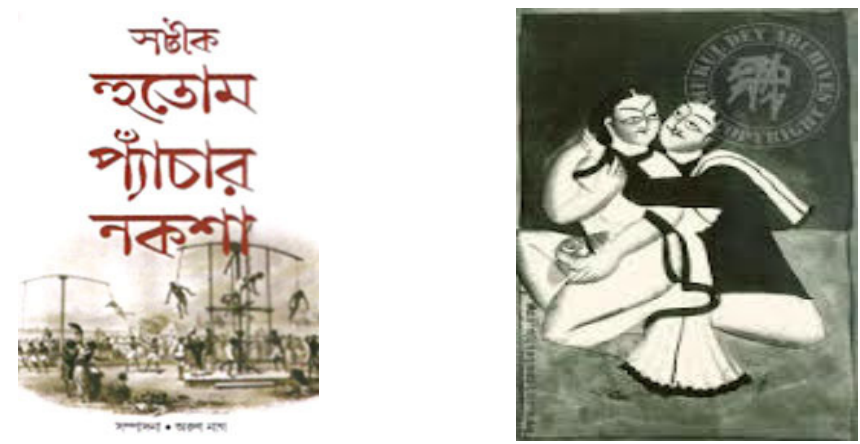
Tutun Mukherjee

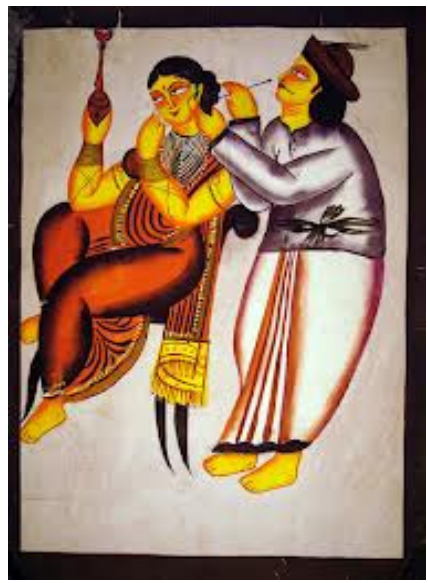

(Hutom Pyanchar Naksha embellished with images: from Google browse on 'patachitra'

https://www.google.co.in/search?q=patachitra+of+kalighat)

Juxtaposing the text with intermedial supplements emphasizes the reader's role in its critical reception. This is an example of what Bourdieu called the "reflexive" sociology of literature that makes the discipline its own object of study and invites interaction between scholars and the existing social conditions.

Another remarkable example is Rabindranath Tagore, the cultural icon of 'modern' India, who found in the juxtaposition of his narratives, poems, songs and paintings the correspondence of the innate rhythm of creativity that could extend the imaginative parameters of an idea and be explored cubist-fashion from different angles as well as the 'movement' or the intermediation between different artistic formulations, rather in the manner of the present concept of intermediality. This was Tagore's way of emphasizing the fluid structure of the creative and artistic landscape, the shifting domains of the 'arts' and the synergy of all arts that blurs and transcends their exclusive disciplinary boundaries. Some examples of his experimentation are as follows: 
Intermediality and Translation:...
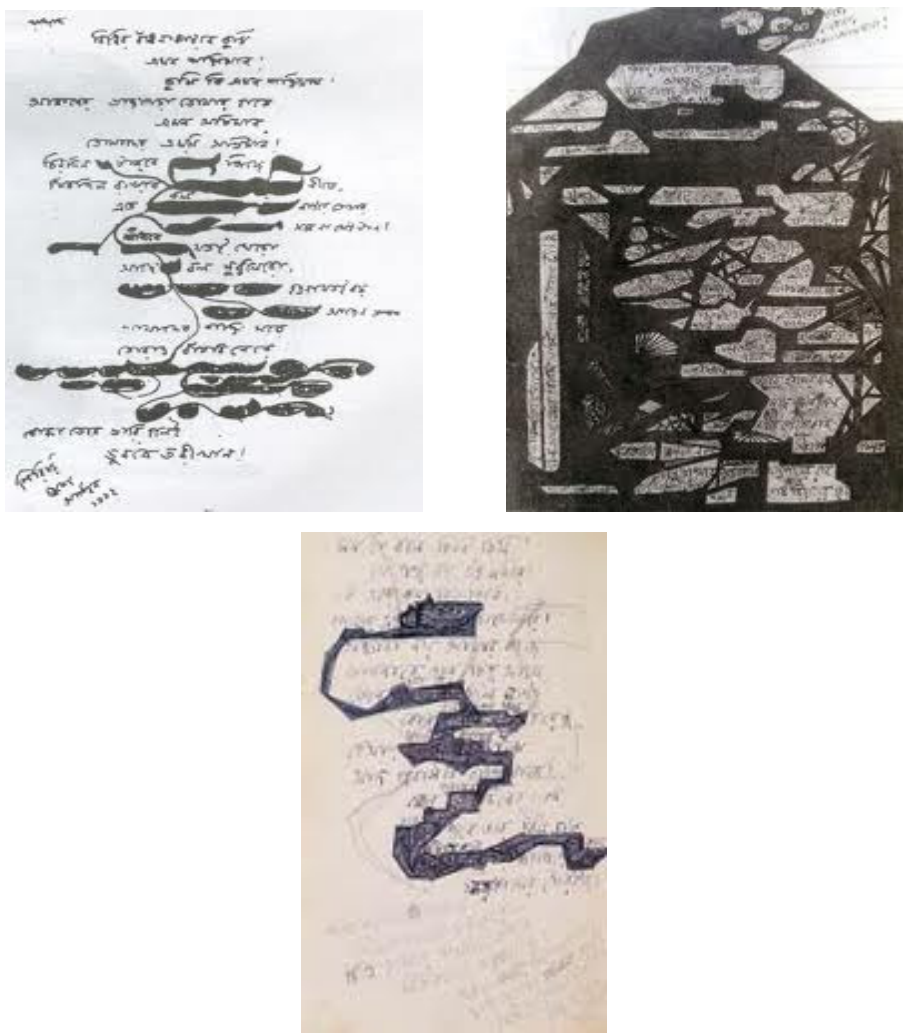

(Images from Tagore's manuscripts:

https://www.google.co.in/search?q=Tagore+poetry+manuscrip ts)

Today, any discussion of Tagore's works requires and is undoubtedly enriched by, the inevitable amalgamation of the different art forms through which a single idea or motif is being expressed. Very intriguing, for instance, is Tagore's ambivalent configuring of 'woman' as both passive as well as an agent of change; patient and calm as well as mysterious and alluring which find expression through his narratives, poems, songs and paintings: 
(https://www.google.co.in/search?q=Rabindranath+Tagore $\% 2$ 7 s+sketches+of+women)

For classroom teaching and even for analytical discussions, Tagore's poems and stories invite inter- and multi-modal approaches which can, by juxtaposition, augment a particular genre with the others and create a conjunction of multiple semiotic systems within the perimeter of single textual space. For instance, the following painting by Tagore can become an exphrasistic extension of his song:

"Shyamol chhaya nai ba gele, sesh boroshar dhara dhele...

Nobin robi utthbe hansi, bajabe megh sonar banshi..."

[Cooling shades, why depart with the last monsoon rains ...

The new sunrise will colour the sky, clouds will play the golden flute...] (translation mine)

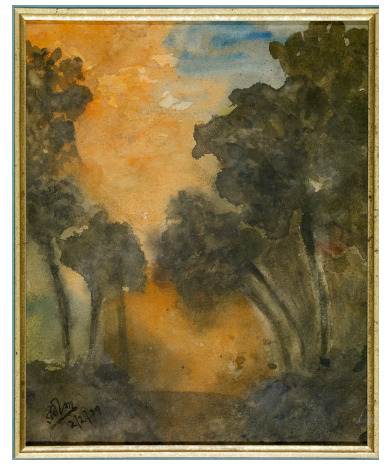

\section{Text-Image Relations}

In fact, such have been the multimedial translations of Tagore's narratives. Filmmakers Satyajit Ray and Tapan Sinha translated several of Tagore's narratives which comprise their best work and are critically acclaimed and awarded. At this instance, three filmic translations are taken as illustrations of the way inter- and multimedia translations extend the appreciation and reception of the original texts. Ray's 
translation of Tagore's novella Nashto Nirh (Broken Nest) as Charulata (1964) and Sinha's translations of Tagore's short stories "Kabuliwala" (1957) and "Atithee" (Visitor) (1966), respectively, gave them contemporaneity and contextual relevance. Ray, for instance, revived the milieu and ambience of $19^{\text {th }}$ century India when the public and the private spheres were clearly demarcated and women were confined to the private domestic space. Although women's education was being encouraged to some extent and Brahmo Samaj movement was trying to inculcate liberal attitude towards women's education, the creative aspirations of women could only find a forum for expression through the print medium. It is ironical that the protagonist Charulata's husband owns a printing press yet she gets her creative writing printed elsewhere. In both the films, the private space of the woman is disturbed by a male outsider. The women are distinguished in their contexts which are problematized and they stand out in their singularity.

Tagore's story "Kabuliwala" was made into a Bengali film by Tapan Sinha in 1957 and in Hindi by Bimal Roy in 1961. The story explores middleclass xenophobia and the stereotyping that govern people's attitudes and operate in social relationships. Afghani traders were commonly seen in cities of India. Tall and sturdy wearing loose-fitting shirt-salwar, Kabuliwalas also lent money and were said to be cruel enforcers to recover the sums and hence in the language they used, their mannerisms and appearance they are 'fearsome foreign strangers'. This stereotype prevails in the xenophobic Bengali mind. An affectionate friendship develops between 'Kabuliwala' Rahmat and a playful and talkative little girl Mini who reminds him strongly of his own small daughter left behind at home. Rahmat gifts her dry fruits and other little items, including a coin, out of affection and enjoys listening to her chatter and shares his nostalgia for his country. But he is 
regarded with suspicion by Mini's mother who thinks he may be a child-lifter. The story narrated by Mini's father tells of a sudden lengthy gap in Rahmat's visits to Mini when he had been jailed for accidentally killing a man while trying to recover money for an expensive shawl sold to him. When he comes to meet Mini again after seven-eight years, it is the day of Mini's marriage. When her father insists Mini meets Rahmat and bid him goodbye, he is amazed to see a young woman dressed in bridal finery. He is reminded of his own daughter who too must have grown to a marriageable age. Mini's father asks Rahmat to bless Mini and gives him money to return to his home and family. Sinha's 1957 film retains the poignancy and emotional sensitivity of the story aided by brilliant acting by the thespian Chhabi Biswas as Kabuliwala Rahmat and small Mini enacted by Tinku Tagore with remarkable élan. Her chatter and lisping call 'Kabuliwala' echo through the film enhance its unique appeal. The story remade in Hindi by Bimal Roy in 1961 and directed by Hemen Gupta was equally memorable with Balraj Sahni in the title role, unforgettable music by Salil Choudhury and cinematography by Kamal Bose. Tagore's short story acquires wonderful intermedial strength with filmic and musical associations.

In the film Atithee (1966) also based on a Tagore story, Sinha recreates the milieu of $19^{\text {th }}$ century rural Bengal. Since the films are character-based, the camera glides ponderingly and with sensitivity on the characters, separate and alone, or in dialogue, capturing every subtle expression and gesture. The women are not the 'objects' of the camera gaze but the camera moves with them in discovering the dimensions of life's experiences in which they are the principal players. The filmmakers extend the stories to encompass many issues that women in India continue to struggle against. Thus, the filmic translations of the stories acquire more impact and wider 
reception in their mediated versions. There are shots and sequences that are purely visual yet speak through powerful and unforgettable images (see Mukherjee). They bring the literary texts alive in ways that wasn't imagined before. The translations deploy and benefit from the coalescence of the dynamics of sight and sound in ways that open up inexhaustible levels of meaning-making. As with all translations, they leave residue for further exploration. Both the cinematic translations received wide critical acclaim and are considered the best work of the two celebrated filmmakers as 'auteur'. Discussing the quality of the work of an 'auteur', film theorist Andrew Sarris explained that though a distinguishable personal style is necessary, that alone cannot be a sufficient condition for being an auteur, maintaining that "Visual style is never an end in itself....Any visual style can be mechanically produced" (110). He regarded the most important attribute to be the distinct expressive quality which arose from that style. He believed that the work of a great auteur manifests an 'interior world' or 'interior meaning' (110). Satyajit Ray's critical acclaim has been based on the reflexive and contemplative quality of his films. Ashis Nandy says Ray's films seem to reveal Ray's secret 'self' which immerses itself in the imaginative contemplation and subsequent configuration of human relationships (235). Tapan Sinha made too many films so not all his films can claim finesse in style and auteur quality but Kabuliwala and Atithee stand out an exceptional translations of Tagore's short stories.

Introducing Liliane Louvel's fascinating book on text/image relations titled Poetics of the Iconotext, Karen Jacobs says, "the demanding pleasures of the literary and pictorial form and their intricate dance with structure" initiate a "infinite dialogue" of inter-relationships (2), especially when intermedial oscillations meld the dynamics of the gaze confronting the texture of lyrics, the lilt of melody and rhythms 
of sound. According to Jacobs, the intersections of sight and hearing augment the confluence of the visceral and cerebral aspects of the reading experience and activate the infinite play of meaning. Such a translation process demands the aesthetics of amalgamation of art forms. Barbara Godard observes in her essay "Translation Poetics, from Modernity to PostModernity": "Translation is understood not as mimesis or imitating, but as poeisis or making with the force of an original and creative act" (92). These are the traits that find expression in the filmic translations by Ray, Sinha and Bimal Roy/Hemen Gupta of Rabindranath Tagore's narratives. The emotional quotient of the films was distinctly raised by the both the poetics of the image, lyrical quality of words and the music.

\section{Intermediality as pedagogy}

Similarly, the domain of education has witnessed the interaction of various types of media, ranging from print media to visual media to multimedia to virtual and digital technologies. Contemporary communication styles manifest the fusion of the paralinguistic, artifactual, kinesic and proxemic features towards re-sensitization of perception and reception. The argument of this paper is to seize upon the promise of new technologies to be harnessed for the purposes of creating more interactive and collaborative teachinglearning environment that demonstrate the manifold crossrelationships between literature and other media. Literature can always accommodate monomedial point-of-view but it becomes much more interesting when studied from comparative media angles. This goes to emphasize the extent to which intermediality offering a range of connections can become relevant to the study of literature.

The thrust of this paper is to explore intermediality for the purposes of translation that can be an alternative model of practice and criticism to the hermeneutics of literary 
interpretation. I propose Intermediality in translation to demonstrate comparative method of analysis because it accommodates dialogue among texts beyond the boundary of a single interpretative system. This requires understanding two aspects of the same proposition: to what extent can translation be an intermedial pursuit and how intermediality can help the process of translation. These in turn raise questions like: (a) how technology can help translation, (b) how intermediality/ multi-modality can enhance the enjoyment of translation, (c) how translation can be a collaborative endeavour. In keeping with the contemporary search for new paradigms and trends incorporating technology in its methodology, intermediality enlarges the scope and function of translation as it not only involves the relationship between different media in the construction of a new text, it also enables the transformation and dispersal of a singular iconotext into multimodal, variously sedimented plural expressivity through intersemiotic recreation/ re-generation. By focusing on the "materialities" of production, intermediality moves away from a meaningfocused approach, the all-pervasiveness of hermeneutics, the conditions of interpretation and the general 'readability' of the text towards questions about material culture - that is, the modalities and carriers of meaning which do not necessarily confine a singular 'meaning'. In other words, it is necessarily to know whether Intermediality and translation share a common hermeneutical predicament. According to Joy Sisley, "where the prefix trans conveys the sense of gap that is nowhere, inter designates the place that is now here. Like the metaphor of the signpost, inter points to many directions at once" (41).

There are three very helpful suggestions which can direct the path of intermedial translation in present times. In her exposition on the new tasks for comparatism in the present context, Gayatri Chakravorty Spivak urges that careful 
attention be paid to the way translation is practiced and undertake translation as active rather than prosthetic endeavour (Spivak 2009: 613). It would then mean that the translation practice must move beyond the simple correspondence of languages and try to 'play' with their materiality. The philosophy of deconstruction suggests that instead of constituting the end product as a synthesis or a unification of the signifier and the signified, the word must be regarded as a force-field of disassociations. Any translation inspired by the concept of the 'floating signifier' would thus search for new intertextualities and associations. Clive Scott suggests that in the context of the intermedial and multimodal possibilities, translation be considered a "centrifugal practice." These processes would mean accommodating more than one correspondence, more than one media. The relevant issues to be addressed are: when one medium aspires to the condition of another or when it adapts a specific instance of another, can this be called 'translation'? If yes, then what gets translated the meaning or the 'affect'?

As seen in the above examples, synthesis of text and image, where each constitutes the horizon of the other, introduces synergy to theoretical discourse about these expressive forms and sheds light on the use of hybrid aesthetic forms. Theorists have acknowledged the ever-extending potential of 'infinite relationships' between text and image. They have also sounded cautionary note about being conscious of the creative force of translating one medium into another that may problematize the ontological and epistemological presumptions about the categories of verbal and visual art. Yet, as explained above, intermedial translation offers immense possibilities. By using hyperlinks, the translator could lead the reader into a network of texts to enhance or nuance as well as augment the variety of the reading experience and thus allow the iconographic monomodal text acquire intermedial plurality. This may be the way 
for translations to push towards new horizons of pedagogy and practice and hold out the creative promise of transforming iconotexts into new sites for reconstructions of meaning.

\section{Computer Assisted Hypertexts as Meaningful, Liberating and Participatory Exercise}

As a pedagogical exercise in class using intermediality, the discussion of any text would suffice. Hypertexts easily enlarge the scope of meaning creation and learner participation. The texts lead to and merge into multiple texts. Let's take a text that figures in most syllabi: Mahasweta Devi's novel in Bengali Hajar Churashir Ma (1974), transcreated as a play and translated by Samik Bandyopadhyay as Mother of 1084 (1998). The Bengali text is available and the English ebook at https://www.elephant-ds.com/LP_TA/index.cfm?T=437583.

The text was also made into a Hindi film and can be watched on youtube at several sites, for example the basic texts available to learners. For the Naxal background required for the text, informative sites are:

https://www.youtube.com/watch?v=zf9-kfiCM4I;

https://www.google.co.in/search?q=Naxal+movement+in+wes t+bengal+in+1960s\&tbm $=$.

A very informative site "Red Shadows of Hope and Despair" is from Outlook:

www.outlookindia.com/magazine/story/httpsred-shadows-ofhope-and-despair/298756 and offers relevant material like films such as Ritwik Ghatak's famous discourse on Reason, Argument and Story -- Jukti Takko aar Gappo (1974) and others to show how the revolution resonated through the world. Discussion of the play is available at:

http://www.allresearchjournal.com/archives/2016/vol2issue5/P artG/2-4-127-211.pdf 
This would bring texts of different kinds into the discussion and understanding of the texts.

For translation workshop, one can take as example the translation of a verse of Bengali nursery rhyme: khoka ghumalo paara juralo bargi elo deshe/bulbulitey dhan kheyeche khajna debo kisey? that talks of the tax burden of the farmers when crops are lost and villages are raided. How to translate this literally? Every word requires attention as do the rhythm and the mnemonic quality. Etymological and historical details would enrich the meaning and can be accessed from Wikipedia about 'bargi' plunder of rural Bengal in late $18^{\text {th }}$ century (approx 1741-1751):

https://en.wikipedia.org/wiki/Bargi;

http://en.banglapedia.org/index.php?title=Maratha_Raids.

Bharatchandra, the court poet of Raja Krishnachandra of Nadia corroborates the bargi plunders in his mangal kavya titled Annadamangal: Katilo bistor lok gram gram pudi/ Lutiya loilo dhon jhiuri bouri. Another poet Gangaram also describes in Maharashtra Purana the destruction and pillaging: “...none escaped, Brahmanas and Vaisnavas, Sannyasis and householders, all had the same fate and cows were massacred along with men". This is detailed at:

http://tarikhpartarikh.blogspot.com/2014/03/the-marathainvasion-of-bengal.html.

The above examples show how translation can use intermedial linking to enhance translation practice to make it a more meaningful, liberating and participatory learning experience.

Keeping in mind the activity of reading as social practice, the relevant questions to pose would be: who reads what, how people read and how their reading can relate to other activities or be further augmented by the multiplication of sensory 
Intermediality and Translation:...

associations, perhaps leading toward a comparative media experience.

\section{References}

FIDLER, Roger. 1997. Mediamorphosis: Understanding New Media. Newbury Park, CA: Pine Forge Press.

GODARD, BARBARA. 2003. Translation Poetics from Modernity to Post-modernity. In Susan Petrilli(ed.), Translation Translation,87-99. Amsterdam and New York: Rodopi.

JACOBS, KAREN. (ed.). 2011. Introduction: Infinite Dialogues. In Liliane Louvel's Poetics of the Iconotext, 1-10. Translated by Laurence Petit. Farnham, Surrey, England \& Burlington, VT, USA: Ashgate Publishing Ltd.

KAtTenbelt, ChIEL. Intermediality: A Redefinition of Media and a Resensibilization of Perception. Online: http://www.heacademy.ac.uk/assets/documents/subjects/pal atine/intermediality.pdf

Louvel, Liliane. 2011. Poetics of the Iconotext. (Ed.) Karen Jacobs. (Trans.) Laurence Petit. Farnham, Surrey, England \& Burlington, VT, USA: Ashgate Publishing Ltd.

MAITY, PRONABESH. 2010. (ed.). Alamkaran: Batatala Theke Halaphila: Illustrations from Bengali Literature. Kolkata: Saptarshi Prakashan.

MukHERJEe, Tutun. 2012. Tagore's Women Protagonists through Ray's Camera: Re-presenting the Shifting Concepts of History, Culture and Identity. In Mohd Asaduddin and Anuradha Ghosh (eds.), Filming Fiction: Tagore, Premchand and Ray, 116-135. New Delhi: Oxford University Press.

NANDY, ASHIS. 1995. The Savage Freud and Other Essays on Possible and Retrievable Selves. Princeton: Princeton University Press.

RAY, SATYAJIT. 1964. Charulata (story by Rabindranath Tagore). Director and Screen Play writer. 
SisLeY, JoY. 2007. Writing, the Body and Cinema: Peter Greenaway's The Pillow Book. In Maddalena Pennacchia Punzi(ed.), Literary Intermediality: The Transit of Literature through Media Circuit. Bern, Berlin, New York, Oxford: Peter Lang. 27-42.

SARRIS, ANDREW. Notes on the Auteur Theroy in 1962. Online: http://alexwinter.com/media/pdfs/andrew_sarris_notes_on_t he-auteur_theory_in_1962.pdf

SCHRÖTER, JENS. Discourses and Models of Intermediality. Online: <http://docs.lib.purdue.edu/clcweb/vol13/iss3/3> SingHA, KALIPRASANNA. 1862/2010. Hutom Pyanchar Noksha. Reprinted as Sothik Hutom Pyanchar Noksha edited by Arun Nag. Calcutta: Anondo Publishers.

SinHA, TAPAN. 1965. Atithee (short story by Tagore). Director and Screenplay Writer.

ScotT, Clive. 2010. Intermediality and Synesthesia: Literary Translation as Centrifugal Practice. Art In Translation, 2(2). 153-170.

SPIVAK, GAYATRI CHAKRAVORTY. 2009. Rethinking Comparativism. New Literary History 40(3). 609-26.

TAgOre, Rabindranath. Paintings by Rabindranath Tagore. Calcutta Web. http://www.calcuttaweb.com/tagore/ paintings.shtml

WOLF, WERNER. 2011. (Inter)mediality and the Study of Literature. CLCWeb: Comparative Literature and Culture 13(3). https://doi.org/10.7771/1481-4374.1789: 2-9. 